\title{
Genetic and phenotypic correlations in plants: a botanical test of Cheverud's conjecture
}

\author{
DAMON E. WAITT*† \& DONALD A. LEVIN \\ $\dagger$ Department of Biology, Southwestern University, Georgetown, TX 78627-0770, U.S.A. and †Department of Botany, \\ University of Texas at Austin, Austin, TX 78713, U.S.A.
}

\begin{abstract}
A survey of the agricultural and evolutionary literature was undertaken to determine the extent to which phenotypic correlations reflect their genetic counterparts in plants. More than 4000 phenotypic and genetic correlations representing 27 different plant species and over 40 years of research were analysed. In 74 per cent of the comparisons, the arrangement of elements of different magnitudes in genetic and phenotypic correlation matrices was more similar than would be expected by chance alone. In addition, the overall magnitude of correlation was greater in genetic correlation matrices than in phenotypic correlation matrices in 85 per cent of the comparisons. Several studies which reported correlations within and among distinct suites of traits provided the opportunity to evaluate correlations among functionally or developmentally related characters. It was determined from these studies that traits belonging to the same suite of characters were more highly genetically and phenotypically correlated than traits from different suites.
\end{abstract}

Keywords: genetic correlation, morphological integration, phenotypic correlation.

\section{Introduction}

According to quantitative genetic theory, genetic and environmental causes of correlation combine together to produce the phenotypic correlation:

$r_{\mathrm{P}}=h_{\mathrm{X}} h_{\mathrm{Y}} r_{\mathrm{A}}+e_{\mathrm{X}} e_{\mathrm{Y}} r_{\mathrm{E}}$,

where $h$ is the square root of the heritability, $e$ represents the square root of the proportion of phenotypic variance attributable to environment, $r$ is the correlation between two traits $\mathrm{X}$ and $\mathrm{Y}$, with subscripts $\mathrm{P}, \mathrm{A}$ and $\mathrm{E}$ representing the phenotypic, additive genetic and environmental correlations, respectively (Falconer, 1989, p. 315). It is clear from the dual nature of the phenotypic correlation that the magnitude and sign of phenotypic and genetic correlations are not necessarily related. In 1988, Cheverud compared 41 pairs of phenotypic and genetic correlation matrices from 23 different animal studies to determine if phenotypic correlations could be substituted for their genetic counterparts in multivariate models of evolutionary change. This surrogate role for phenotypic correlations was motivated by the fact that genetic correlations are

*Correspondence. E-mail: waittd@southwestern.edu often difficult (require large sample sizes of individuals of known relatedness) or impossible (rare, endangered or extinct species) to obtain (Cheverud, 1988). In comparison, phenotypic correlations are easily and accurately estimated requiring only moderate sample sizes and no knowledge of relatedness among individuals. Although Cheverud's (1988, p. 958) conclusion that "phenotypic correlations are likely to be fair estimates of their genetic counterparts in many situations' has been called into question on statistical grounds (Willis et al., 1991), his hypothesis is valuable in that it emphasizes a holistic view of evolutionary change and the importance of correlations in our understanding of functional and developmental relationships among traits (cf. Mayr, 1976; Lewontin, 1978; Gould \& Lewontin, 1979).

The present investigation was motivated by the absence of a synthetic overview of genetic and phenotypic correlations in plants. It is intended to serve as a botanical companion to Cheverud's (1988) synthesis of the animal literature and as a reference for investigators in plant genetics. In general, the relationship between phenotypic and genetic correlations in plants is poorly understood. Given the manifest plasticity of plants vs. animals (Bradshaw, 1965; Schlichting, 1986; Sultan, 1987), we might expect 
that environmental alteration of the plant phenotype will result in phenotypic correlations that are not very good estimates of their genetic counterparts. In order to determine whether this expectation is realized, we generated a database of paired genetic and phenotypic correlation matrices from a variety of plant studies. Using this database, we were able to compare genetic correlation matrices with their phenotypic counterparts, as well as evaluate phenotypic and genetic correlations among suites of functionally and/or developmentally related traits (sensu Olson \& Miller, 1958; Berg, 1959, 1960).

\section{Materials and methods}

\section{Data}

A survey of the agricultural and evolutionary literature yielded 32 plant studies in which the author(s) reported both genetic and phenotypic correlation matrices (see Appendix). From the studies reporting correlations of both types for four or more traits, we derived a data set consisting of 53 pairs of genetic and phenotypic correlation matrices. Several studies included pairs of genetic and phenotypic correlation matrices from more than one environment, population, generation, etc. Together, the data encompass more than 40 years of research, 27 different species and over 4000 phenotypic and genetic correlations.

Several studies were selected for closer inspection from the pool of studies, because they reported phenotypic and genetic correlations within and among distinct suites of traits (see Appendix). These studies were especially useful in that they allowed us to evaluate phenotypic and genetic correlations among traits sharing a common function and/or developmental origin.

\section{Data analyses}

The overall magnitude of correlation within a matrix or subset thereof was measured as the average absolute value of individual correlations within the matrix or subset of traits. That is, the absolute values of all off-diagonal nonredundant elements were summed and divided by the number of off-diagonal nonredundant elements to arrive at the average absolute value of correlation. That is,

$\bigoplus=\frac{\Sigma\left|r_{i, j}\right|}{n}$ for $i \neq j$,

where $r_{i, j}$ refers to the correlation between characters $i$ and $j$, and $n$ is the number of off-diagonal nonredundant elements in the matrix.
We calculated the average disparity between corresponding genetic and phenotypic correlation matrices or subsets thereof to assess how close, on average, were the estimates of genetic and phenotypic correlation. The average disparity between a pair of correlation matrices was determined by averaging the absolute values of differences between corresponding off-diagonal nonredundant elements of the phenotypic and genetic correlation matrices or subsets thereof (Willis et al., 1991). That is,

$D=\frac{\Sigma\left|r_{\mathrm{G}, i, j}-r_{\mathrm{P}, i, j}\right|}{n}$, for $i \neq j$

where $r_{\mathrm{G}, i, j}$ and $r_{\mathrm{P}, i, j}$ refer to genetic and phenotypic correlations between characters $i$ and $j$, and $n$ is the number off-diagonal nonredundant elements in a matrix. The average disparity indicates the overall difference in the magnitude of correlation between matrices or subsets thereof, whereas the average absolute value of correlation indicates the overall magnitude of correlation within a matrix or subset thereof.

A Pearson product-moment correlation between corresponding off-diagonal nonredundant elements of two correlation matrices was employed to measure the pattern similarity of corresponding genetic and phenotypic correlation matrices (cf. Lofsvold, 1986; Cheverud, 1988, 1989; Kohn \& Atchley, 1988; Cheverud et al., 1989; Cowley \& Atchley, 1990; Wagner, 1990; Roff, 1995). The matrix correlation which measures the similarity of the arrangement of elements of different magnitudes in two matrices is given by

$$
r_{\mathrm{AB}}=\frac{\sum_{i, j=1}^{n}\left(a_{i j}-a_{i j}\right)\left(b_{i j}=b_{i j}\right)}{\sqrt{\sum_{i, j=1}^{n}\left(a_{i j}-a_{\mathrm{ij}}\right)^{2} \sum_{i, j=1}^{n}\left(b_{i j}-b_{i j}\right)^{2}}} \text { for } i \neq j,
$$

where $a_{i, j}$ and $b_{i, j}$ are the $i$ th, $j$ th elements of the correlation matrices being compared (A and $\mathbf{B})$, $\mathbf{a}_{i j}$ and $\boldsymbol{b}_{i j}$ are the means of all off-diagonal elements in matrices $\mathbf{A}$ and $\mathbf{B}$, respectively, and $n$ is the number of characters sampled (Sneath \& Sokal, 1973). A large positive matrix correlation indicates that genetic and phenotypic correlations vary in similar directions, not that the magnitudes of individual correlations are identical. For this reason, it is important to consider the matrix correlation and average disparity (see above) together. If the matrix correlation is high and the average disparity is low, then genetic and phenotypic correlations with 
similar magnitudes tend to occupy the same positions in their respective matrices.

The statistical significance of the matrix correlation cannot be based on parametric or nonparametric hypothesis tests because any two correlations within the same row or column of a correlation matrix exhibit dependence. In this regard, randomization tests are useful because they require no prior assumptions regarding the distribution of the test statistic. The statistical significance of the matrix correlation was tested using Mantel's randomization test (Mantel, 1967) which has been the subject of considerable discussion (Shaw, 1991, 1992; Cowley \& Atchley, 1992). In this test procedure, the observed matrix correlation is compared to an empirically derived distribution of matrix correlations based on the null hypothesis of no similarity between genetic and phenotypic correlation matrices. The empirical distribution of matrix correlations is generated by repeatedly (1000 permutations per comparison) calculating the matrix correlation between genetic and phenotypic correlation matrices after first having randomized the genetic correlation matrix. The proportion of randomly permuted matrix correlations exceeding the observed one gives an estimate of the probability of obtaining a matrix correlation greater than the observed one by chance. If the probability is large $(P>0.05$ for example), then there is a failure to reject the null hypothesis, and the matrices being compared are no more similar than by chance alone. Conversely, if the probability is small $(P<0.05$ for example), then the null hypothesis of no pattern similarity between correlation matrices can be rejected, and the alternative hypothesis of pattern similarity accepted.

\section{Results}

\section{Magnitude and disparity}

The overall magnitude of genetic correlation as measured by the average absolute value had a mean value of 0.400 across studies compared with a mean value of 0.312 for the average absolute value of phenotypic correlation (Table 1). The overall magnitude of correlation was greater in the genetic correlation matrices than in the corresponding phenotypic correlation matrices in 85 per cent of the comparisons (Table 1). A graphical representation of this discrepancy can be seen in Fig. 1. Note that the majority of points occur above the line of equality in this figure signifying a greater average absolute value of genetic correlation.
Table 1 Comparison of corresponding pairs of genetic and phenotypic correlation matrices in plants. The sources are identified by number in the Appendix. $\left|R_{\mathrm{G}}\right|$ and $\left|R_{\mathrm{P}}\right|$ are the average absolute values of genetic and phenotypic correlations, respectively, and $D$ is the average disparity. $r_{\mathrm{M}}$ is the matrix correlation between genetic and phenotypic correlation matrices. $P_{r_{\mathrm{M}}}$ is the proportion of permutation matrix correlations exceeding the observed matrix correlation. $P_{r_{\mathrm{M}}}$ gives the probability of obtaining a matrix correlation this high, or higher, by chance under the null hypothesis of no pattern similarity between genetic and phenotypic correlation matrices. If $P_{r_{\mathrm{M}}}$ is less than the table-wide significance level of 0.001 , then we reject the null hypothesis of no pattern similarity

\begin{tabular}{|c|c|c|c|c|c|}
\hline Source & $\left|R_{\mathrm{G}}\right|$ & $\left|R_{\mathrm{P}}\right|$ & $D$ & $r_{\mathrm{M}}$ & $P_{r_{\mathrm{M}}}$ \\
\hline 1 & 0.248 & 0.230 & 0.129 & 0.870 & 0.001 \\
\hline $2 \mathrm{a}$ & 0.328 & 0.223 & 0.139 & 0.902 & 0.001 \\
\hline $2 b$ & 0.375 & 0.235 & 0.193 & 0.747 & 0.001 \\
\hline $3 a$ & 0.264 & 0.211 & 0.078 & 0.964 & 0.001 \\
\hline $3 b$ & 0.281 & 0.205 & 0.117 & 0.866 & 0.001 \\
\hline 4 & 0.311 & 0.277 & 0.055 & 0.984 & 0.001 \\
\hline 5 & 0.424 & 0.403 & 0.031 & 0.998 & 0.001 \\
\hline $6 a$ & 0.420 & 0.365 & 0.190 & 0.852 & 0.001 \\
\hline $6 b$ & 0.214 & 0.283 & 0.177 & 0.783 & 0.001 \\
\hline $7 \mathrm{a}$ & 0.479 & 0.458 & 0.508 & 0.677 & 0.005 \\
\hline $7 b$ & 0.473 & 0.311 & 0.207 & 0.900 & 0.001 \\
\hline $8 a$ & 0.252 & 0.190 & 0.081 & 0.865 & 0.001 \\
\hline $8 b$ & 0.218 & 0.125 & 0.124 & 0.739 & 0.001 \\
\hline $8 c$ & 0.112 & 0.106 & 0.052 & 0.896 & 0.001 \\
\hline $8 d$ & 0.219 & 0.177 & 0.082 & 0.895 & 0.001 \\
\hline 9 & 0.982 & 0.689 & 0.096 & 0.995 & 0.001 \\
\hline 10 & 0.339 & 0.270 & 0.087 & 0.986 & 0.001 \\
\hline 11 & 0.559 & 0.520 & 0.095 & 0.976 & 0.001 \\
\hline $12 \mathrm{a}$ & 0.548 & 0.406 & 0.175 & 0.946 & 0.001 \\
\hline $12 b$ & 0.495 & 0.358 & 0.201 & 0.926 & 0.001 \\
\hline $12 \mathrm{c}$ & 0.465 & 0.283 & 0.249 & 0.865 & 0.001 \\
\hline $12 d$ & 0.451 & 0.308 & 0.184 & 0.944 & 0.001 \\
\hline 13 & 0.523 & 0.371 & 0.163 & 0.959 & 0.001 \\
\hline 14 & 0.410 & 0.347 & 0.140 & 0.951 & 0.001 \\
\hline 15 & 0.543 & 0.295 & 0.288 & 0.888 & 0.001 \\
\hline $16 \mathrm{a}$ & 0.203 & 0.200 & 0.009 & 0.998 & 0.001 \\
\hline $16 b$ & 0.458 & 0.186 & 0.288 & 0.809 & 0.001 \\
\hline $16 c$ & 0.221 & 0.221 & 0.054 & 0.962 & 0.001 \\
\hline $16 \mathrm{~d}$ & 0.960 & 0.194 & 0.809 & NA & NA \\
\hline 17 & 0.505 & 0.361 & 0.165 & 0.972 & 0.001 \\
\hline 18 & 0.310 & 0.212 & 0.102 & 0.956 & 0.001 \\
\hline 19 & 0.565 & 0.319 & 0.465 & 0.441 & 0.028 \\
\hline $20 \mathrm{a}$ & 0.375 & 0.337 & 0.038 & 0.997 & 0.001 \\
\hline $20 \mathrm{~b}$ & 0.340 & 0.322 & 0.042 & 0.998 & 0.001 \\
\hline 21 & 0.641 & 0.399 & 0.338 & 0.818 & 0.027 \\
\hline 22 & 0.649 & 0.489 & 0.814 & NA & NA \\
\hline 23 & 0.352 & 0.370 & 0.102 & 0.953 & 0.001 \\
\hline 24 & 0.542 & 0.436 & 0.183 & 0.959 & 0.001 \\
\hline 25 & 0.380 & 0.191 & 0.259 & 0.668 & 0.001 \\
\hline 26 & 0.514 & 0.305 & 0.389 & 0.300 & 0.106 \\
\hline
\end{tabular}

(c) The Genetical Society of Great Britain, Heredity, 80, 310-319. 
Table 1 Continued

\begin{tabular}{lccccc}
\hline Source & $\left|R_{\mathrm{G}}\right|$ & $\left|R_{\mathrm{P}}\right|$ & $D$ & $r_{\mathrm{M}}$ & $P_{r_{\mathrm{M}}}$ \\
\hline 27a & 0.695 & 0.489 & 0.266 & 0.747 & 0.004 \\
27b & 0.724 & 0.658 & 0.068 & 0.967 & 0.001 \\
28 & 0.280 & 0.262 & 0.124 & 0.817 & 0.001 \\
29a & 0.191 & 0.213 & 0.221 & 0.469 & 0.050 \\
29b & 0.193 & 0.153 & 0.170 & 0.864 & 0.124 \\
30 & 0.372 & 0.188 & 0.276 & 0.673 & 0.001 \\
31 & 0.545 & 0.457 & 0.228 & 0.417 & 0.176 \\
32a & 0.163 & 0.353 & 0.279 & 0.616 & 0.002 \\
32b & 0.182 & 0.292 & 0.206 & 0.772 & 0.002 \\
32c & 0.137 & 0.337 & 0.280 & 0.764 & 0.002 \\
32d & 0.255 & 0.352 & 0.280 & 0.395 & 0.010 \\
32e & 0.226 & 0.326 & 0.221 & 0.662 & 0.002 \\
32f & 0.287 & 0.267 & 0.215 & 0.649 & 0.004 \\
\hline
\end{tabular}

NA, not available.

Although the average absolute value of correlation gives an indication of the overall strength of the individual correlations within a matrix, it obscures the actual disparity between corresponding individual genetic and phenotypic correlations because it is derived from absolute values. For this reason, we also calculated the average disparity between corresponding off-diagonal nonredundant elements in the genetic and phenotypic correlation matrices. The

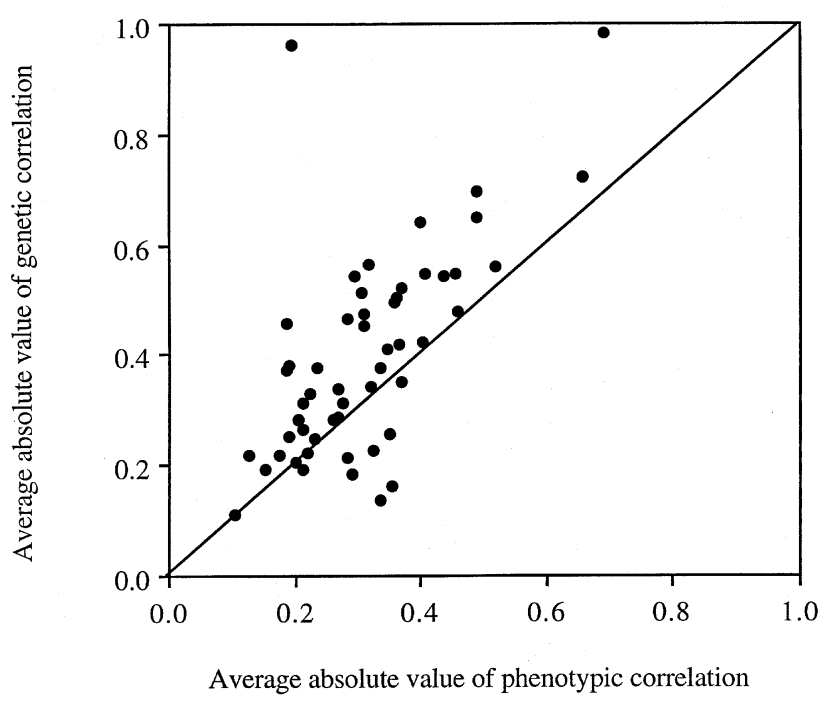

Fig. 1 Plot of the average absolute value of genetic correlation vs. the average absolute value of phenotypic correlation for each of the 53 matrix pairs. The diagonal line represents equality of the average absolute value of genetic and phenotypic correlation. Points which lie off this line represent matrix pairs in which the overall magnitude of genetic and phenotypic correlation within a matrix are not identical. average disparity ranged from a low of 0.009 (source 16a) to a high of 0.814 (source 22) with an average of 0.202 across studies (Table 1 ).

\section{Pattern similarity}

The arrangement of elements of different magnitudes within corresponding genetic and phenotypic correlation matrices or pattern similarity was measured by the matrix correlation, and ranged from 0.300 (source 26) to 0.998 (sources 5, 16a and $20 \mathrm{~b}$ ) with an average value of 0.836 across the studies (Table 1). At a table-wide significance level of $0.001,74$ per cent of the matrix correlations were more similar than would be predicted by chance alone (94 per cent of the matrix correlations were more similar at an individual significance level of $0.05)$.

We plotted average disparities against matrix correlations in order to determine if pattern similarity resulted from proportional equivalence without similarity in magnitude of corresponding correlations or whether pattern similarity was caused by similarity in magnitude of corresponding genetic and phenotypic correlations (Fig. 2). It can be seen from this figure, that the two variables are inversely proportional to one another so that a small average disparity between corresponding genetic and phenotypic correlation matrices is associated with a high degree of pattern similarity as measured by the

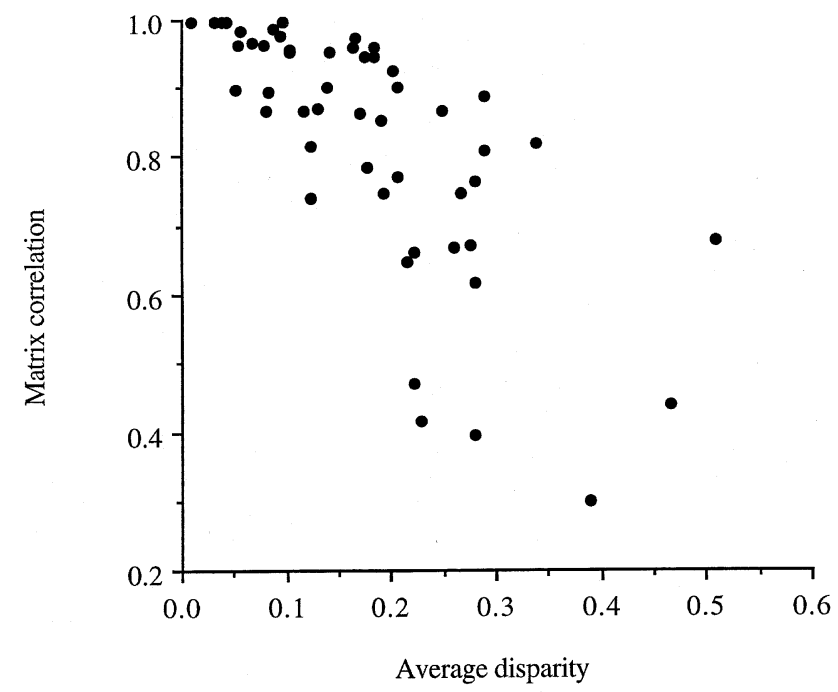

Fig. 2 Plot of pattern similarity between corresponding genetic and phenotypic matrices as measured by the matrix correlation vs. the average absolute value of differences between corresponding off-diagonal nonredundant elements of the phenotypic and genetic correlation matrices or average disparity for each of the matrix pairs. 
matrix correlation. These results clearly indicate that pattern similarity as measured by the matrix correlation between corresponding genetic and phenotypic correlation matrices results from the arrangement of elements of similar magnitudes in genetic and phenotypic correlation matrices.

\section{Character suites}

Distinct suites of functionally and/or developmentally related traits were identified by the authors in five different studies including our own (Appendix sources: 18, 24, 25, 28 and 32). For example, Harding et al. (1990; source 24) reported phenotypic and genetic correlations within and among three distinct suites of floral traits in Gerbera hybrida, Compositae. We took the liberty of constructing correlation diagrams from the data reported in this study to illustrate the concept of phenotypic and genetic integration among characters (Fig. 3). The three traits of the ray floret suite are not very highly genetically or phenotypically integrated with one another corresponding to a low average absolute value of genetic and phenotypic correlation within this suite of traits (Table 2). In contrast, traits of the trans floret suite, and to a lesser extent the disk floret suite, exhibit a higher degree of genetic and phenotypic character integration (Fig. 3, Table 2). According to Berg $(1959,1960)$ and Olson \& Miller (1958), we might expect the level of genetic and phenotypic correlation between suites of traits to be less than the level of genetic and phenotypic correlation within suites in this study. In fact, with the exception of ray floret traits, this was the case (Table 2).

We averaged the within-suite magnitudes of correlation in each study and compared it to the overall magnitude of between-suite correlation in each study to determine if the results from other studies were consistent with Harding et al. (1990; source 24). In every study, the within-suite average for genetic correlations was greater than the between-suite average (Table 2). By the same token, the within-suite average for phenotypic correlations was greater than the between-suite average in every case (Table 2).

\section{Discussion}

Phenotypic correlations appear to be as good as, or better, estimates of their genetic counterparts in plants (our results) than in animals. Unfortunately, our results on average disparity are not directly comparable with Cheverud's (1988) because his measure of the average difference between corresponding genetic and phenotypic correlation minimizes the actual disparity (Willis et al., 1991). In both this study and Cheverud's (1988), the similarity of genetic and phenotypic correlation patterns was evaluated using the matrix correlation. Cheverud reports an average matrix correlation across animal studies of 0.57 with 78 per cent of the matrix correlations being significantly different from zero at the 5 per cent probability level. In comparison, the plant literature yielded an average matrix correlation of 0.82 with 94 per cent of the matrix correlations being significantly different from zero at the 5 per cent probability level. Thus, the overall pattern of
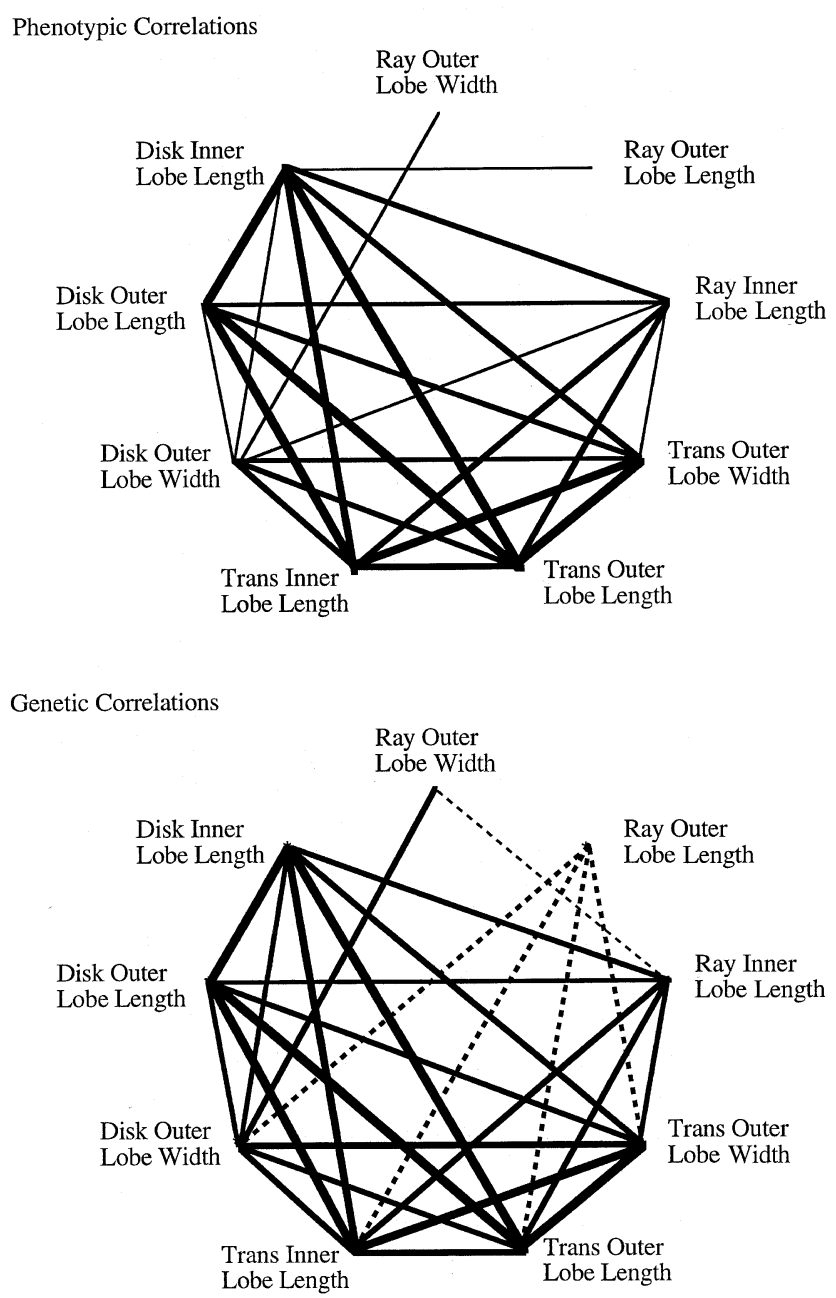

Fig. 3 Phenotypic and genetic correlations within and among suites of traits in Gerbera hybrida (source 24). Positive correlations among traits are represented by solid lines connecting the traits. Negative correlations among traits are represented by dashed lines. Line thicknesses indicate the overall magnitude of each correlation: $0.25 \leq$ thin $\leq 0.49,0.50 \leq$ medium $\leq 0.74,0.75 \leq$ thick $\leq 1.0$. 
Table 2 Comparisons of genetic and phenotypic correlations within and among suites of traits. Studies can be identified by source number in the Appendix. Ntrts is the number of traits within a suite and Ncorr is the number of correlations within or between suites. $\left|R_{\mathrm{G}}\right|$ and $\left|R_{\mathrm{P}}\right|$ are the average absolute values of genetic and phenotypic correlations either within or between suites of traits

\begin{tabular}{|c|c|c|c|c|c|}
\hline Source & Suites & Ntrts & Ncorr & $\left|R_{\mathrm{G}}\right|$ & $\left|R_{\mathrm{P}}\right|$ \\
\hline \multirow{8}{*}{18} & 1. Vegetative & 3 & 3 & 0.604 & 0.312 \\
\hline & 2. Panicle & 2 & 1 & 0.320 & 0.194 \\
\hline & 3. Kernel & 5 & 10 & 0.425 & 0.386 \\
\hline & Within-suite average & & & 0.450 & 0.297 \\
\hline & Suite 1 with 2 & & 6 & 0.484 & 0.319 \\
\hline & Suite 1 with 3 & & 15 & 0.167 & 0.110 \\
\hline & Suite 2 with 3 & & 10 & 0.215 & 0.101 \\
\hline & Between-suite average & & & 0.289 & 0.177 \\
\hline \multirow[t]{8}{*}{24} & 1. Ray floret & 3 & 3 & 0.167 & 0.107 \\
\hline & 2. Trans floret & 3 & 3 & 0.937 & 0.840 \\
\hline & 3. Disk floret & 3 & 3 & 0.713 & 0.617 \\
\hline & Within-suite average & & & 0.606 & 0.521 \\
\hline & Suite 1 with 2 & & 9 & 0.414 & 0.261 \\
\hline & Suite 1 with 3 & & 9 & 0.359 & 0.268 \\
\hline & Suite 2 with 3 & & 9 & 0.789 & 0.693 \\
\hline & Between-suite average & & & 0.521 & 0.407 \\
\hline \multirow[t]{8}{*}{25} & 1. Achene and head & 8 & 28 & 0.456 & 0.275 \\
\hline & 2. Size and shape & 3 & 3 & 0.403 & 0.510 \\
\hline & 3. Life history & 6 & 15 & 0.438 & 0.269 \\
\hline & Within-suite average & & & 0.432 & 0.351 \\
\hline & Suite 1 with 2 & & 24 & 0.430 & 0.213 \\
\hline & Suite 1 with 3 & & 48 & 0.310 & 0.110 \\
\hline & Suite 2 with 3 & & 18 & 0.327 & 0.130 \\
\hline & Between-suite average & & & 0.356 & 0.151 \\
\hline \multirow[t]{8}{*}{28} & 1. Floral & 6 & 15 & 0.410 & 0.492 \\
\hline & 2. Leaf & 2 & 1 & 0.840 & 0.860 \\
\hline & 3. Life history & 2 & 1 & 0.110 & 0.030 \\
\hline & Within-suite average & & & 0.453 & 0.461 \\
\hline & Suite 1 with 2 & & 12 & 0.208 & 0.126 \\
\hline & Suite 1 with 3 & & 12 & 0.181 & 0.125 \\
\hline & Suite 2 with 3 & & 4 & 0.205 & 0.130 \\
\hline & Between-suite average & & & 0.198 & 0.127 \\
\hline \multirow[t]{8}{*}{$32 b$} & 1. Floral & 3 & 3 & 0.078 & 0.323 \\
\hline & 2. Vegetative & 5 & 10 & 0.530 & 0.705 \\
\hline & 3. Leaf & 2 & 1 & 0.218 & 0.499 \\
\hline & Within-suite average & & & 0.275 & 0.509 \\
\hline & Suite 1 with 2 & & 15 & 0.041 & 0.213 \\
\hline & Suite 1 with 3 & & 6 & 0.124 & 0.072 \\
\hline & Suite 2 with 3 & & 10 & 0.107 & 0.098 \\
\hline & Between-suite average & & & 0.091 & 0.128 \\
\hline \multirow[t]{8}{*}{$32 \mathrm{e}$} & 1. Floral & 3 & 3 & 0.065 & 0.446 \\
\hline & 2. Vegetative & 5 & 10 & 0.589 & 0.745 \\
\hline & 3. Leaf & 2 & 1 & 0.259 & 0.691 \\
\hline & Within-suite average & & & 0.304 & 0.627 \\
\hline & Suite 1 with 2 & & 15 & 0.098 & 0.278 \\
\hline & Suite 1 with 3 & & 6 & 0.113 & 0.109 \\
\hline & Suite 2 with 3 & & 10 & 0.169 & 0.038 \\
\hline & Between-suite average & & & 0.127 & 0.142 \\
\hline
\end{tabular}


genetic and phenotypic correlation also appears to be more similar in plants than in animals.

There are two possible explanations for greater correspondence of $r_{\mathrm{P}}$ and $r_{\mathrm{G}}$ in plants compared to animals. First, nearly all of the plant data were based on populations reared under garden, laboratory or greenhouse conditions. Willis et al. (1991) have argued that such conditions decrease environmental variation and inflate heritabilities and genetic correlations in laboratory populations. Consequently, the correspondence between $r_{\mathrm{P}}$ and $r_{\mathrm{G}}$ will be greater in the laboratory than in the field. Although this explanation highlights the importance of not extrapolating from the laboratory to the field, it does little to explain the discrepancy between our work and Cheverud's, as both surveys rely heavily on results obtained under uniform conditions. Secondly, the correspondence between $r_{\mathrm{P}}$ and $r_{\mathrm{G}}$ may be greater in the plant studies because genetic correlations were estimated with greater precision. Cheverud (1988) demonstrated that as sample size increased, the precision with which genetic correlations are estimated also increased, the difference between genetic and phenotypic correlations decreased, and genetic correlations were more similar in pattern to their phenotypic counterparts. Cheverud (1988) divided the animal studies into two samples with effective sample sizes greater than and less than 40 . The set of studies with larger sample sizes yielded an average matrix correlation of 0.81 , similar to that reported here $(0.82)$. Because the effective sample size was greater than 40 in nearly every plant study, it seems likely that the greater correspondence between $r_{\mathrm{P}}$ and $r_{\mathrm{G}}$ in plants may simply be an artifact of sample size.

We expected to find less similarity in levels and patterns of genetic and phenotypic correlation in plants than in animals given the manifest plasticity of plants. Unfortunately, the available data do not simulate the environmental conditions necessary for the realization of phenotypic plasticity. One would expect to find that the level of correspondence between genetic and phenotypic correlations would decrease as environmental variability increases. It would be interesting to test this expectation by comparing phenotypic correlations derived from several sources (field, garden and greenhouse) with genetic correlations derived under uniform conditions.

In 1958, Olson \& Miller coined the phrase morphological integration to describe high levels of phenotypic correlation within suites of functionally or developmentally related traits and proposed that such suites form the units of evolution. Berg (1959) gave a selective explanation for morphological integration by postulating that pollinator selection would favour the integration of floral dimensions if it increased the precision with which pollen is deposited by insects. Berg (1960) also postulated that a reduction in correlation between floral and vegetative traits would be selectively advantageous if it isolated floral traits from the selective forces experienced by vegetative traits. Our evaluation of character suites indicates that traits belonging to the same functional and/or developmental group are phenotypically more integrated than traits with different functions or developmental origins. Berg's expectation that phenotypic correlations will be greater within floral and vegetative character suites than among them has been documented in five species of insect-pollinated plants (Conner \& Sterling, 1996), wild radish (Conner \& Via, 1993) and Phlox drummondii (Waitt \& Levin, 1993). Furthermore, traits belonging to the same functional and/or developmental group are genetically more integrated than traits with different functions or developmental origins (Conner \& Via, 1993; Waitt \& Levin, source 32). Clearly, there is greater genetic and phenotypic character integration within suites of functionally or developmentally related traits than between them.

Life history characters may or may not be an exception to the general rule of greater genetic and phenotypic character integration within than among suites of traits. In Conner \& Via's wild radish study, the within-suite average for life history traits was less than the between-suite average for both genetic and phenotypic correlations (source 28). Conversely, the within-suite average for life history traits was greater than the between-suite average for both genetic and phenotypic correlations in Heterosperma pinnatum (Venable \& Búrquez, source 25). More studies containing matrices with mixtures of morphological and life history characters are required before a general relationship between life history and morphological traits can be established in plants.

\section{Conclusion}

With respect to the populations, environments, traits, sample sizes and other peculiarities of the studies cited here, phenotypic correlations are a good reflection of their genetic counterparts in plants. Although the precision necessary for accurate evolutionary inference is not likely to be met by substituting phenotypic correlations for genetic ones, qualitative predictions based on phenotypic correlations are far better than nothing when genetic data are impossible to obtain.

(C) The Genetical Society of Great Britain, Heredity, 80, 310-319. 


\section{References}

AKORODA, M. 1984. Variability, repeatability, character correlation and path coefficient analyses in yellow yam. Theor. Appl. Genet., 69, 217-221.

AL-JibOURI, H., MILlER, P. AND ROBINSON, H. 1958. Genotypic and environmental variances and covariances in an upland cotton cross of interspecific origin. Agron. J., 50, 633-636.

BERG, R. L. 1959. A general evolutionary principle underlying the origin of developmental homeostasis. Am. Nat., 93, 103-105.

BERG, R. L. 1960. The ecological significance of correlation pleiades. Evolution, 14, 171-180.

BRADSHAw, A. D. 1965. Evolutionary significance of phenotypic plasticity in plants. Adv. Genet., 13, 115-155.

CAHANER, A. AND HILLEL, J. 1980. Estimating heritability and genetic correlation between traits from generations $\mathrm{F}_{2}$ and $\mathrm{F}_{3}$ of self-fertilizing species: a comparison of three methods. Theor. Appl. Genet., 58, 33-38.

CHEVERUD, J. M. 1988. A comparison of genetic and phenotypic correlations. Evolution, 42, 958-968.

CHEVERUD, J. M. 1989. A comparative analysis of morphological variation patterns in the papionins. Evolution, 43, 1737-1747.

CHEVERud, J. M., WAGNer, G. P. AND DOW, M. M. 1989. Methods for the comparative analysis of variation patterns. Syst. Zool., 38, 201-213.

CONNER, J. AND VIA, s. 1993. Patterns of phenotypic and genetic correlations among morphological and lifehistory traits in wild radish, Raphanus raphanistrum. Evolution, 47, 704-711.

CONNER, J. K. AND STERling, A. 1996. Selection for independence of floral and vegetative traits: evidence from correlation patterns in five species. Can. J. Bot., 74, 642-644.

COOPER, J. P. 1960. Selection and population structure in Lolium. IV. Correlated response to selection. Heredity, 14, 229-246.

COWLEY, D. E. AND ATCHLEY, W. R. 1990. Development and quantitative genetics of correlation structure among body parts of Drosophila melanogaster. Am. Nat., 135, 242-268.

COWley, D. E. AND ATCHLEy, W. R. 1992. Comparison of quantitative genetic parameters. Evolution, 46, 1965-1967.

CUARtero, J. AND CUBero, J. 1982. Phenotypic, genotypic and environmental correlations in tomato (Lycopersicon esculentum). Euphytica, 31, 151-159.

DEWEY, D. AND LU, K. 1959. A correlation and path-coefficient analysis of components of crested wheatgrass seed production. Agron. J., 51, 515-518.

ECOCHARD, R. AND RAVELOMANANTSOA, Y. 1982. Genetic correlations derived from full-sib relationships in soybean (Glycine max Merr.). Theor. Appl. Genet., 63, 9-15.

ESTILAI, A., EHDAIE, B., NAQVI, H. H., DIERIG, D. A., RAY, D. T. AND THOMPSON, A. E. 1992. Correlations and path analyses of agronomic traits in guayule. Crop Sci., 32, 953-957.

FALCONER, D. S. 1981. Introduction to Quantitative Genetics, 2nd edn. Longman, London.

GOULD, S. J. AND LEWONTIN, R. C. 1979. The spandrels of San Marco and the Panglossian paradigm: a critique of the adaptationist programme. Proc. R. Soc. B., 205, 581-598.

HARDING, J., HUANG, H. H., BYRNE, T. AND HUANG, N. 1990. Quantitative analysis of correlations among flower traits in Gerbera hybrida Compositae. Theor. Appl. Genet., 80, $552-558$.

IBRAHIM, O. E., NYQUIST, W. E. AND AXTELL, J. D. 1985. Quantitative inheritance and correlations of agronomic and grain quality traits of sorghum. Crop Sci., 25, 649-654.

JOHNSON, H., ROBINSON, H. AND COMSTOCK, R. 1955. Genotypic and phenotypic correlations in soybeans and their implications in selection. Agron. J., 47, 477-483.

KANG, M. S., MILleR, J. D. AND TAI, P. Y. P. 1983. Genetic and phenotypic path analyses and heritability in sugarcane. Crop Sci., 23, 643-647.

KELly, C. A. 1993. Quantitative genetics of size and phenology of life-history traits in Chamaecrista fasciculata. Evolution, 47, 88-97.

KHAN, I. 1985. Correlation and path coefficient analysis of yield components in mung bean (Phaseolus aureus Roxb.). Bot. Bull. Academia Sinica, 26, 13-20.

KOHN, L. A. AND ATCHLEY, w. R. 1988. How similar are genetic correlation structures? Evolution, 42, 467-481.

LANDE, R. 1979. Quantitative genetic analysis of multivariate evolution, applied to brain:body size allometry. Evolution, 33, 402-416.

LeWontin, R. C. 1978. Adaptation. Sci. Am., 239, 213-231.

LOFSVOLD, D. 1986. Quantitative genetics of morphological differentiation in Peromyscus. I. Tests of the homogeneity of genetic covariance structure among species and subspecies. Evolution, 40, 559-573.

LOTHROP, J. E., ATKINS, R. E. AND SMITH, O. S. 1985. Variability for yield and yield components in IAP1R grain sorghum random-mating population. II. Correlations, estimated gains from selection, and correlated responses to selection. Crop Sci., 25, 240-244.

MANTEL, N. 1967. The detection of disease clustering and a generalized regression approach. Cancer Res., 27, 209-220.

MAYR, E. 1976. Evolution and the Diversity of Life. Harvard University Press, Cambridge, MA.

MAZER, S. J. 1989. Family mean correlations among fitness components in wild radish: controlling for maternal effects on seed weight. Can. J. Bot., 67, 1890-1897.

MITCHELL, R. J. AND SHAw, R. G. 1993. Heritability of floral traits for the perennial wild flower Penstemon centranthifolius (Scrophulariaceae): clones and crosses. Heredity, 71, 185-192.

MITCHELL-OLDS, T. 1986. Quantitative genetics of survival and growth in Impatiens capensis. Evolution, 40, 107-116. 
OLSON, E. C. AND MILlER, R. L. 1958. Morphological Integration. University of Chicago Press, Chicago, IL.

O'NEIL, P. AND SCHMITT, J. 1993. Genetic constraints on the independent evolution of male and female reproductive characters in the tristylous plant Lythrum salicaria. Evolution, 47, 1457-1471.

PANDEYA, R. S., DIRKS, V. A. AND POUSHINSKY, G. 1983. Quantitative genetic studies in flue-cured tobacco (Nicotiana tabacum). I. Agronomic characters. Can. J. Genet. Cytol., 25, 336-345.

PARODA, R. AND JOSHI, A. 1969. Correlations, path coefficients and the implication of discriminant function for selection in wheat (Triticum aestivum). Heredity, 12, 383-392.

ROBERTS, D. D., KRONSTAD, W. E. AND HAUNOLD, A. 1980. Genetic variability and association of maturity, yield, and quality characteristics of female hops. Crop Sci., 20, 523-527.

ROBINSON, H., COMSTOCK, R. AND HARVEY, P. 1951. Genotypic and phenotypic correlations in corn and their implications in selection. Agron. J., 43, 282-287.

ROFF, D. A. 1995. The estimation of genetic correlations from phenotypic correlations: a test of Cheverud's conjecture. Heredity, 74, 481-490.

RUBAIHAYO, P. AND MAKUMBI, v. 1976. Heterosis, inbreeding depression, and correlation coefficients of yield and yield components of sorghum. Z. Pflzücht, 77, 286-295.

SCHLichting, C. D. 1986. The evolution of phenotypic plasticity in plants. Ann. Rev. Ecol. Syst., 17, 667-693.

SCHWAEGERLE, K. A. AND LEVIN, D. A. 1991. Quantitative genetics of fitness traits in a wild population of Phlox. Evolution, 45, 169-177.

SHAw, R. G. 1991. The comparison of quantitative genetic parameters between populations. Evolution, 45, 143-151.

SHAw, R. G. 1992. Comparison of quantitative genetic parameters: reply to Cowley and Atchley. Evolution, 46, 1967-1969.

SINGH, B. P. AND CHOWDHURY, R. K. 1983. Correlation and path coefficient analysis of seed yield and oil content in mustard (Brassica juncea). Can. J. Genet. Cytol., 25, 312-317.

SNEATH, P. H. AND SOKAL, R. R. 1973. Numerical Taxonomy. W. H. Freeman, San Francisco, CA.

SOLTIS, P. 1986. Estimates of heritability and correlations of morphometric traits in Clarkia (Onagraceae). Theor. Appl. Genet., 73, 88-93.

SUltAN, s. E. 1987. Evolutionary implications of phenotypic plasticity in plants. Evol. Biol., 21, 127-178.

TAN, G.-Y. AND DUNN, G. M. 1976. Genetic variation in stomatal length and frequency and other characteristics in Bromus inermis Leyss. Crop Sci., 16, 550-553.

VAN VALEN, L. 1965. The study of morphological integration. Evolution, 19, 347-349.

VENABLE, D. L. AND BÚRQUEZ, A. 1990. Quantitative genetics of size, shape, life-history, and fruit characteristics of the seed heteromorphic composite Heterosperma pinnatum. Correlation structure. Evolution, 44, 1748-1763.
WAGNER, G. P. 1990. A comparative study of morphological integration in Apis mellifera (Insecta, Hymenoptera). Z. Zool. Systemat. Evol.-forsch., 28, 48-61.

WAITT, D. E. AND LEVIN, D. A. 1993. Phenotypic integration and plastic correlations in Phlox drummondii Hook. (Polemoniaceae). Am. J. Bot., 80, 1224-1233.

WEBER, C. AND MOORTHY, B. 1952. Heritable and nonheritable relationships and variability of oil content and agronomic characters in the $\mathrm{F}_{2}$ generation of soybean crosses. Agron. J., 44, 202-209.

Willis, J. H., COYNe, J. A. AND KiRKPATRICK, M. 1991. Can one predict the evolution of quantitative characters without genetics? Evolution, 45, 441-444.

WRIGHT, s. 1980. Genic and organismic selection. Evolution, 34, 825-843.

\section{Appendix}

The following is a list of sources used in the present study. For each source, the author(s), year of publication, species, and number and types of traits is given. Alphabetic entries $(\mathrm{a}, \mathrm{b}, \mathrm{c}, \ldots)$ refer to multiple pairs of genetic and phenotypic correlations matrices from a single source.

1 Robinson et al. (1951), Zea mays, eight agronomic traits.

2 Weber \& Moorthy (1952), Glycine max, seven agronomic traits. Two crosses: (a) Adams $\times$ Hawkeye, (b) Habaro $\times$ Mandell.

3 Johnson et al. (1955), Glycine max, 24 agronomic traits. Two populations: (a) Roanoke $\times$ Palmetto, (b) $\mathrm{N} 42-26 \times$ Seminole.

4 Al-Jibouri et al. (1958), Gossypium hirsutum, eight agronomic traits.

5 Dewey \& Lu (1959), crested wheatgrass, six agronomic traits.

6 Cooper (1960), Lolium perenne, seven agronomic traits. Two populations: (a) Kent, (b) Irish.

7 Paroda \& Joshi (1969), Triticum aestivum, five agronomic traits. Two generations: (a) $F_{1}$, (b) $F_{2}$.

8 Rubaihayo \& Makumbi (1976), Sorghum bicolor, nine agronomic traits. Multiple crosses: (a) P4/P2, (b) P4/P1, (c) P3/P1, (d) P3/P5.

9 Tan \& Dunn (1976), Bromus inermis, nine leaf traits.

10 Cahaner \& Hillel (1980), Arachis hypogaea, six agronomic traits.

11 Roberts et al. (1980), Humulus lupulus, nine agronomic traits.

12 Cuartero \& Cubero (1982), Lycopersicon esculentum, seven agronomic traits. Four environments: (a) glasshouse/plastic, (b) glasshouse/soil, (c) open air/plastic, (d) open air/soil.

13 Ecochard \& Ravelomanantsoa (1982), Glycine

(C) The Genetical Society of Great Britain, Heredity, 80, 310-319. 
$\max , 14$ agronomic traits.

14 Kang et al. (1983), Saccharum spp., 12 agronomic traits.

15 Pandeya et al. (1983), Nicotiana tabacum, 12 agronomic traits.

16 Singh \& Chowdhury (1983), Brassica juncea, eight agronomic traits. Four environments: (a) rainfed and high fertility, (b) rainfed and low fertility, (c) irrigated and high fertility, (d) irrigated and low fertility.

17 Akoroda (1984), Dioscorea cayenensis, seven agronomic traits.

18 Ibrahim et al. (1985), Sorghum bicolor, 10 traits in three suites.

19 Khan (1985), Phaseolus aureus, seven agronomic traits.

20 Lothrop et al. (1985), Sorghum bicolor, four agronomic traits. Two experiments: (a) 1978-80, (b) 1981-82.

21 Mitchell-Olds (1986), Impatiens capensis, six vegetative traits.

22 Soltis (1986), Clarkia spp., 11 floral traits.

23 Mazer (1989), Raphanus raphanistrum, 11 vegetative and life history traits.
24 Harding et al. (1990), Gerbera hybrida, nine traits in three suites.

25 Venable \& Búrquez (1990), Heterosperma pinnatum, 17 traits in three suites.

26 Schwaegerle \& Levin (1991), Phlox drummondii, five traits.

27 Estilai et al. (1992), Parthenium argentatum, seven agronomic traits. Two locations: (a) Maricopa, AZ, (b) Riverside, CA.

28 Conner \& Via (1993), Raphanus raphanistrum, 10 traits in three suites.

29 Kelly (1993), Chamaecrista fasciculata, 10 traits: (a) six floral, (b) four vegetative.

30 Mitchell \& Shaw (1993), Penstemon centranthifolius, seven floral traits.

31 O'Neil \& Schmitt (1993), Lythrum salicaria, four floral traits.

32 Waitt \& Levin (1994), Phlox drummondii, 10 traits in three suites. Two populations and three environments: (a) Elgin at 200 p.p.m. NPK, (b) Elgin at 600 p.p.m. NPK, (c) Elgin at 1000 p.p.m. NPK, (d) Lexington at 200 p.p.m. NPK, (e) Lexington at 600 p.p.m. NPK, (f) Lexington at 1000 p.p.m. NPK. 